\title{
THE INFLUENCE OF SLOPING CLOUD IN THE VISUAL FIELD ON THE COGNITIVE DETERMINANTS OF MILITARY PILOTS' BEHAVIOR
}

\section{HANNA BEDNAREK ${ }^{1}$, MICHAŁ JANEWICZ ${ }^{1,2}$, and MAGDALENA PRZEDNICZEK ${ }^{1}$}

${ }^{1}$ University of Social Sciences and Humanities, Warsaw, Poland

Department of Psychology

${ }^{2}$ Military Institute of Aviation Medicine, Warsaw, Poland

Aeromedical Training Division

\begin{abstract}
Objectives: The study analyzed the effectiveness of military pilots' behavior under the influence of false horizon illusion - a false perception of the real horizon. It was assumed that visual illusion tends to cause spatial disorientation (SD). The question was asked which orientation of the sloping cloud (right/left) would have a bigger impact on SD. The effectiveness of the flight profile performance under the influence of visual illusion was analyzed in the context of the field dependence (FD), field independence (FI) or field intermediate dependence (FINT) of perception, the effectiveness of attention and operational memory. Material and Methods: The study covered 66 pilots. A flight simulator was used as a measure of effectiveness in performing the flight profile in spatial disorientation conditions. The effectiveness of attention and working memory was diagnosed using 4 computer tasks. Results: It was revealed that the right sloping cloud (compared to the left sloping cloud) had a greater impact on military pilots' behavior. The cognitive style distinguishes the accuracy of the flight profile performance from the inclined cloud pointing to the right. The comparisons showed significant differences between the FI and FD pilot groups. All the pilots demonstrated the right-sided asymmetry of the flight rate. While performing tasks on the simulator, the FI pilots were characterized by a more stable rate than the FINT pilots. Conclusions: A general conclusion is that the "correct falling cloud" had a greater impact on pilots' behavior. The presented results confirm the hypothesis that susceptibility to visual illusions is significantly increased in the pilots characterized by field dependence while the pilots with the FINT style of perception are characterized by a greater variability of the flight rate. Int J Occup Med Environ Health. 2019;32(5):653-62
\end{abstract}

Key words:

memory, attention, false horizon illusion, spatial disorientation, military pilots, field-dependent/independent

\section{INTRODUCTION}

This study examined the efficiency of military pilots' behavior under false horizon illusion - a misperception of the actual horizon [1]. The sloping cloud in the visual field is perceived as a horizontal line; therefore, it was assumed that such visual illusion tends to produce spatial disorienta- tion (SD) [2]. The question was asked which orientation of the sloping cloud, right or left, would have a greater impact on SD. In this study, the authors focused not only on the influence of the $10^{\circ}$ sloping cloud in the visual field (clockwise and counterclockwise) on the effectiveness of pilots' behavior, but they also took into account other cognitive

Received: January 14, 2019. Accepted: July 10, 2019.

Corresponding author: Michał Janewicz, University of Social Sciences and Humanities, Department of Psychology, Chodakowska 19/31, 03-815 Warsaw, Poland (e-mail: michal.janewicz@gmail.com). 
variables, including the dependence on/the independence from the field, as well as attention and memory.

Which orientation of the sloping cloud, right or left, would have a greater impact on SD?

The authors assumed that physical stimulation features appearing in a specific information processing context contribute to the creation of an erroneous mental model of the situation that causes SD. The authors were looking for answers to the question about individual differences in the formation of SD, and the question of which cognitive variables favored higher efficacy in the flight profile performance in the false horizon in 2 task conditions: the sloping cloud in the visual field clockwise and counterclockwise.

Firstly, the efficiency of the flight profile performance under the influence of the false horizon illusion was analyzed in the context of the dependent/independent style of perception [3-5], along with empirical evidence for the usefulness of the field dependent-independent construct (FDI) in understanding spatial orientation. The FDI style influences an organization of the visual field. Moreover, under the influence of gravitational force, subjects' change in the position of their body is guided by visual information. The above mentioned phenomena (a rod and frame, and tilted room effects) happen when an individual has to integrate contradictory information from visual, vestibular and proprioceptive systems. Therefore, this type of a visuo-cognitive conflict is similar to the one which pilots face while flying an aircraft. The field dependence (FD), labeled also as a global style or passive-global orientation, is a method of data transformation that is characterized by a slow and diffuse understanding of figure-ground relations (Embedded Figure Test - EFT), a generally slower perception, and the formation and alteration of perception schemata [6]. The field-independent (FI) style results in a greater flexibility and autonomy of perception [7]. Secondly, the authors aimed at identifying the cognitive determinants of the pilots' behavior efficiency in SD con- ditions. They searched among elementary cognitive processes such as attention and memory, information selection mechanisms, resistance to distraction, and the efficiency of the visuo-spatial sketch pad in working memory [8-10]. When considering the efficacy of pilots' behavior during simultaneous tasks, e.g., a motor task of navigating an aircraft and a perceptual task of scanning the visual field, it is important to highlight the role of the central executive system, as described by Baddeley [11], Baddeley and Della Sala [12], and Miyake et al. [13], or of the controlled attention described by Engle [14]. The central executive controls multitasking through allocating attentional resources, information updating and inhibiting a predominant, automatic response. On the basis of the working memory model proposed by Baddeley and Logie [15], one can assume that a lower efficacy of attention control mechanisms contributes to the creation of an inaccurate mental model of position, attitude and movement of both the pilot and aircraft in space.

In view of the above, the following 3 hypotheses were tested:

1. In the condition with the right sloping cloud in the visual field (the false horizon condition), pilots will perform a flight profile characterized by a greater right-side asymmetry and greater variability than in the control conditions.

2. In the false horizon condition (the sloping cloud in the visual field, either clockwise or counterclockwise), field-independent pilots will show greater accuracy in performing the flight profile (less asymmetry and variability of a flight rate) than pilots with an intermediate or field-dependent style of perception.

3. In the false horizon condition, pilots with a better selective and divided attention, and higher memory capacity and processing speed, will be more accurate in performing the flight profile (less asymmetry and variability of a flight rate). 


\section{MATERIAL AND METHODS}

The study covered 66 military pilots, aged $32.3 \pm 6.58$ years, with the total flight time of $1006.73 \pm 79.35 \mathrm{~h}$. A flight simulator was used as a measure of effectiveness in performing the flight profile in spatial disorientation conditions. The pilots did not undergo any previous training or tests using this flight simulator. The effectiveness of attention and working memory was diagnosed using 4 computer tasks. There were 2 independent sessions. The first one involved measuring the cognitive functions and the second one included an experimental task on a flight simulator. The break was approx. 2 weeks. The total study session time was 105 min. The study was approved by the local Ethical Commission at the University of Social Science and Humanities (registered as 5/11/2008) and complied with the Helsinki Declaration: Medical Research Involving Human Subjects. All the participants provided their written informed consent prior to the study.

As mentioned earlier, the study used 4 computer-based tests to asses cognitive functions of the study group. Descriptions of the performed tasks are provided below. The Embedded Figure Test [16] was used to asses the category to which the test subjects belonged, i.e., whether they were field dependent, independent or intermediately dependent (Figure 1). The subjects were instructed to find simple geometric shapes embedded in more complex figures with an emerging pattern. The test variant that was used for this purpose consisted of 24 tasks. The test subjects were required to trace the contour of a simple figure using a stylus on a touch screen (Figure 1). Time was used as a field dependence indicator.

To measure selective and divided attention, the Divided Attention (DIVA) task [17] was used. The information selection efficiency, distractibility and the amount of attentional resources were measured. In the DIVA test the type of the task (single and dual), the number of letter-stimuli on the computer screen $(3,4$ and 5$)$, the level of distrac-
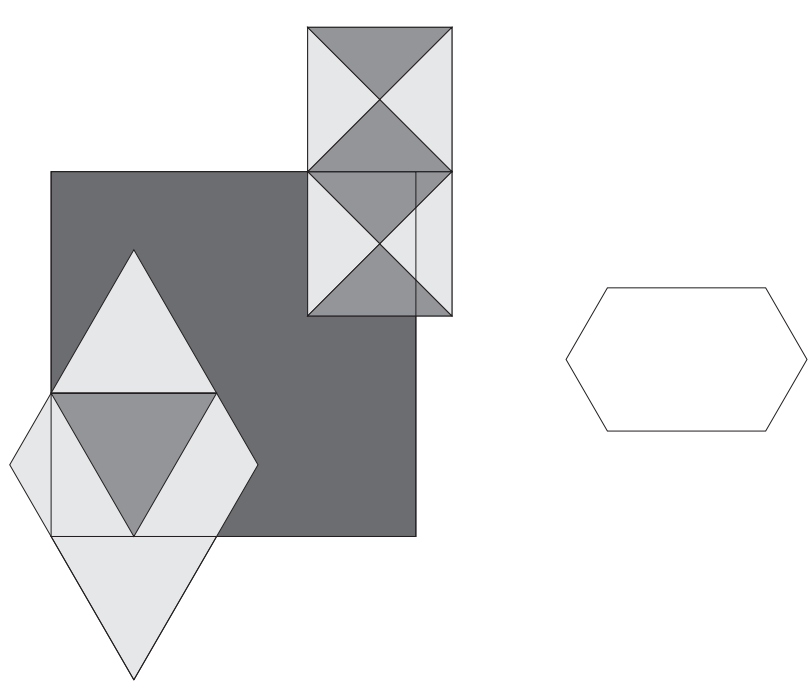

Figure 1. Embedded Figure Test (sample)

tion (presence or absence of a distracter), and the series (the whole procedure is repeated 3 times) were all taken into account when performing the diagnostic process.

In the dual task condition, the priority task was administered concurrently with the secondary task that is based on a signal detection paradigm [18]. Stimuli-letters were presented on the computer screen in 2 frames. The smaller frame showed a letter of the alphabet indicating the pattern. If the pattern was in uppercase, the task required reacting by clicking the left mouse button on every lowercase letter, referred to as a stimulus, which appeared on the screen and which matched the pattern. If the pattern was in lowercase, the subjects should react accordingly to the above mentioned. The pattern changed every 20 s. During the $20 \mathrm{~s}$ period, 4 relevant stimuli emerged to which the participants were required to respond. The exposure time of a single stimulus was $850 \mathrm{~ms}$. In half of the conditions distractors appeared, in addition to the relevant and irrelevant stimuli. These were letter-stimuli physically consistent with the pattern. All of the irrelevant stimuli as well as distractors should be ignored.

The second task was introduced in the second part of the DIVA test. This task was performed simultaneously with the above mentioned. It involved regulation of the 


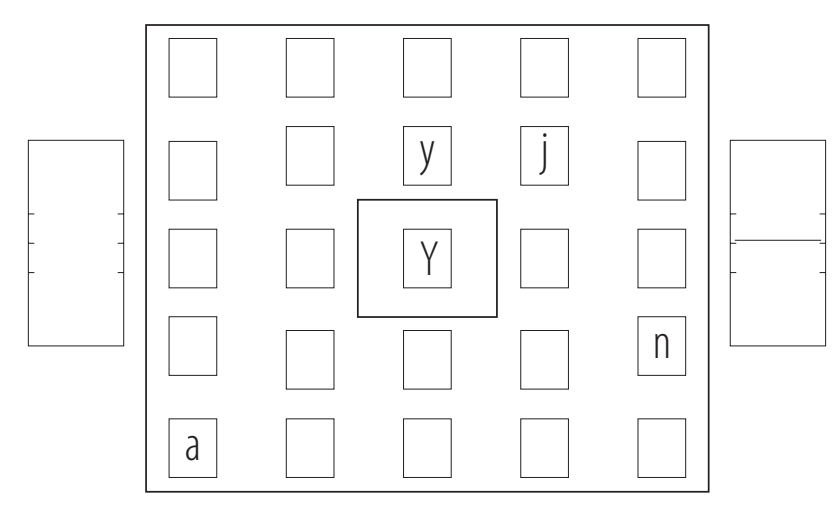

Figure 2. Divided Attention (DIVA) task

position of a line which moved inside one of the rectangles (Figure 2). The excessive falling or rising of the line caused the computer to generate a sound $(\mathrm{A}=440 \mathrm{~Hz})$. The DIVA task took an average of about $30 \mathrm{~min}$ to finish. False alarms (FA), omissions (OM) and the time of correct detections indicated the correctiveness of the performance. In the secondary task, a deviation of the line from the optimum was measured, along with the subjects' reaction time (expressed by the duration of the sound signaling a mistake).

The Switching of Attention (SWATT) task was used to assess both the efficiency of selective attention and working memory capacity. In the procedure, the center of the screen showed 2 digits with 2 letters underneath. The stimuli changed every $800 \mathrm{~ms}$. The participants were asked to press the button every time they saw 2 identical letters or 2 odd digits [19]. The testing sequence consisted of 100 pairs of numbers and 100 pairs of letters (Figure 3). It included 12 pairs of numerical patterns (odd numbers) and 12 pairs of alphabetical patterns (2 identical letters). The numerical and alphabetical patterns cannot appear simultaneously and are separated by at least 1 non-pattern (interval of $800 \mathrm{~ms}$ ). The total number of errors (omissions of letters and numbers, and false alarms) adds to the overall efficacy of attention. Additionally, it is possible to calculate how quickly performing the task becomes automatic (a drop

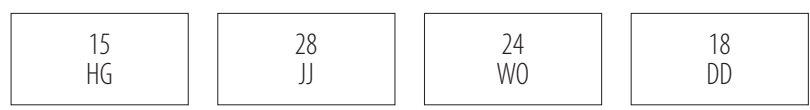

Figure 3. Switching of Attention (SWATT) task

in the number of errors and a shorter reaction time in subsequent trials).

Working memory capacity, processing speed and working memory updating were assessed by the Memory and Attention (MMATT) task. The MMATT is a somewhat modified n-back test paradigm [20]. The participants were instructed to store and update, in real time, only the most recent number and to press the response button only when recognizing the number repetition. The target number could have been presented on 4 possible positions (1-, 2-, 3-, or 4- back). Each stimulus was presented for $2000 \mathrm{~ms}$, followed by a 500 ms mask. A beep indicated false alarm errors. The pilots took 1 practice session before taking the test. The total number of omissions and false alarm errors was used as an updating score [19, 20].

The Hyperion flight simulator was used. The Hyperion is a simulator made with training pilots and assessing the efficacy of the spatial orientation in mind. It simulates a flight on a twin-engine jet fighter aircraft, MIG-29. It provides a high resolution representation of the scenery and shows an extensive field of view. Its wide-angle lens, ranging $180^{\circ}$ horizontally and $27^{\circ}$ vertically (picture resolution of $8000 \times 1200 \mathrm{px}$ ), assure particularly good representations of the peripheral parts of the view.

The projector, the heart of the simulator, is placed on a skeleton frame made of metal. The Hyperion is capable of simulating flight above clouds, which may be particularly tricky for the pilot, especially when flying without an artificial horizon indicator (one of the cockpit instruments that is key for maintaining spatial orientation). It has been assumed that while flying above clouds the pilot perceives the horizon created by the cloud's deck as horizontal (Figure $4 \mathrm{a}$ and $4 \mathrm{~b}$ ), and as a result adjusts the position of the plane accordingly to this perception. 
d)

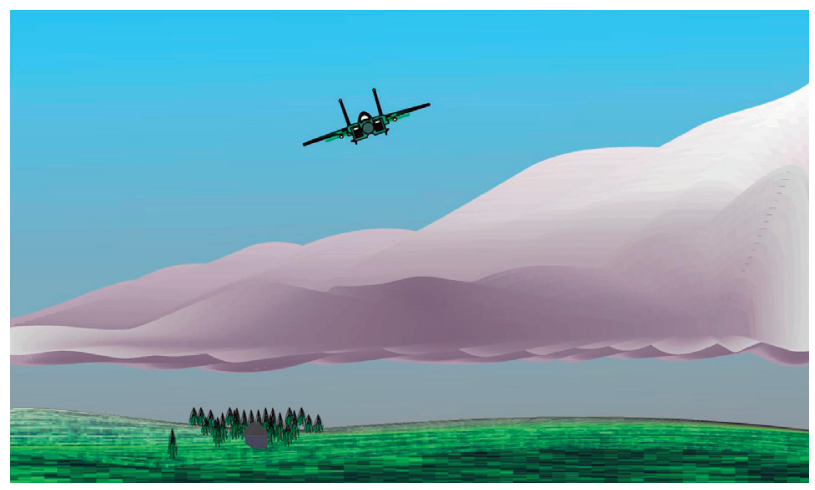

b)

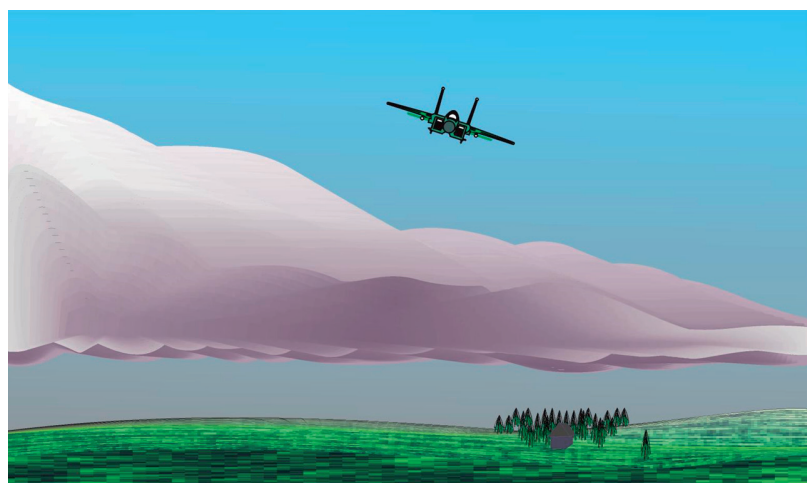

Figure 4. The Hyperion flight simulator. Simulation of a false horizon illusion - the sloping cloud tilted a) clockwise and b) counterclockwise

The study involved executing 3 flight profiles:

1. A profile without any visual illusions - the control condition.

2. A profile with the simulation of a false horizon illusion the cloud deck tilted $10^{\circ}$ clockwise.

3. A profile with the simulation of a false horizon illusion the cloud deck tilted $10^{\circ}$ counterclockwise.

The experimental manipulation involved presenting a sloping cloud in the visual field and switching off an artificial horizon indicator. The pilots were briefed and received written instructions that included a graphic representation of the flight profiles. The subjects were asked to sit on a chair in the simulator, about $80 \mathrm{~cm}$ away from flight instruments and $120 \mathrm{~cm}$ away from mirrors (that represented their visual field), and they had no eye contact with the simulator technician. The experiment took about $10 \mathrm{~min}$. Beforehand all the pilots were given 5-10 min for test flights which provided an opportunity to train the subjects in using the simulator. From every flight profile simulated, a 3-min sample was chosen, and a $60 \mathrm{~s}$ long section of the flight was analyzed. The operator/technician was monitoring the real-time flight profile and flight instruments from a separate room.

Input data were: altitude 0-2200 m, cloudiness 10/10, cloud base $300 \mathrm{~m}$, cloud deck $2000 \mathrm{~m}$, rate $300^{\circ}$, with the phase without an artificial horizon indicator (with a non-operational instrument) beginning at $1800 \mathrm{~m}$.

When the aircraft reached above $2000 \mathrm{~m}$, flying above the cloud deck and with the artificial horizon inoperative, a sloping cloud appeared in the pilot's visual field (Figure $4 \mathrm{a}$ and $4 \mathrm{~b}$ ). The cloud was tilted clockwise $10^{\circ}$ to the left or to the right - depending on the flight profile. After reaching $2000 \mathrm{~m}$, all the discrepancies from the assumed flight profile were registered and evaluated (the assumed flight path was 300 s $)$. As the simulator is characterized by high fidelity and an extensive field of view, a slight, but big enough, 10 ş tilt was used to prevent the pilots from an easy identification of the experimental manipulation. The variability and asymmetry of heading were used as indicators of the flight rate.

\section{RESULTS}

Based on the rate asymmetry index, it turned out that the cognitive style differentiates the accuracy of the profile, with the sloping cloud pointing to the right $F(2.63)=$ 3.25, $\mathrm{p}<0.05$. Multiple comparisons (performed using the Bonferroni method) showed significant differences between the group of FI (0.119) and FD pilots (0.436) $(\mathrm{p}<0.5)$. All the pilots demonstrated the right-side asymmetry of heading, as evidenced by the positive value of 
the analyzed indicator. However, the pilots who preferred a field-dependent style were less immune to this visual illusion than the pilots independent of the field.

The variability of heading also differentiates the accuracy of the flight profile performance, depending on the preferred cognitive style $F(2.63)=5.03, p<0.001$. In terms of the variability index, post hoc tests did not show any differences between the FD pilots (0.0162) and the FI pilots $(0.0123)(p>0.05)$, and there were no differences between the pilots with a field-dependent style (0.0162) and a mixed (intermediate) style (0.022) ( $p>0.05)$. However, there were some differences in the stability of the flight between the FI and field intermediate (FINT) pilot groups $(\mathrm{p}<0.01)$.

Under the influence of the oblique cloud to the right, there were no differences due to the preferred styles in terms of the average rate and average roll $(\mathrm{p}>0.05)$. The presented research results have confirmed the hypothesis that the susceptibility to visual illusions is significantly increased in the pilots characterized by field dependence.

In order to predict the change of the rate which the aircraft would take under the influence of an oblique cloud tilted $10^{\circ}$ to the right, several analyses were performed on the basis of the functioning of attention and working memory by means of multiple regression (an input method). First, several models for the entire pilot group were explored and tested. Then, the model that obtained the best fit to the data was verified among the pilots with a dependent, mixed or field-independent style.

For the variable explaining rate, a model containing the following variables was chosen: information selection efficiency, divisibility of attention when performing simultaneous tasks, the efficiency of information refresh in working memory, and the capacity and updating of working memory.

In the above model, there are 2 predictors which, when controlling other variables in the model, allow predict- ing the asymmetry of the flight rate in a significant way. The smaller capacity and weaker update of the short-term stored information in working memory is a stronger predictor ( $\hat{\mathrm{a}}=0.315 ; \mathrm{p}<0.05)$ than information selection efficiency ( $\hat{a}=0.294, p<0.05)$.

The significance of this model $\mathrm{F}(5.57)=4.564$ was obtained; $p<0.001$; however, the value of $r_{c}=0.223$ indicates its poor adjustment to empirical data. The model explains about $22 \%$ of the variance. The sign and values of â coefficients obtained by the surveyed pilots indicate that the lower the memory capacity and the weaker the update of stored information in the working memory, and the more false positives errors in the selection of information, the more right-handed asymmetry of heading (greater spatial disorientation).

Then, by predicting the course that the aircraft would take with regard to the preferred cognitive style, the above-described set of variables in the field-dependent pilots group was tested. A high level of fit of the model to the empirical data, $r_{c}=0.41(F(5.13)=3.933, p<0.05)$, was obtained. It was shown that, in the case of the field-dependent pilots, 2 cognitive variables significantly affected the asymmetry of the flight rate. The predictors that allow predicting the level of a dependent variable according to the strength of the relationship are: committing a greater number of false alarms when selecting information (efficiency of selective attention) ( $\hat{a}=0.580, p<0.05)$ and a shorter time for simultaneous tasks ( $\hat{\mathrm{a}}=-0,495, \mathrm{p}<0.05$ ). In the fielddependent pilots group, both predictors, while controlling the other variables in the model, explain $41 \%$ of the variance.

In the group of the pilots with an intermediate style, the tested model also proved statistically significant $\mathrm{F}$ (5.13) $=3.16, \mathrm{p}<0.05$. However, in this group, only 1 predictor regarding the functioning of working memory ( $\hat{\mathrm{a}}=0.441$, $\mathrm{p}<0.05$ ) was statistically significant. The lower the efficiency of updating information in the memory and the smaller the memory capacity, the greater the asymmetry 
of heading. An adjustment of the above model to the data in the group of the pilots with a mixed style is moderate, as evidenced by value $\mathrm{r}_{\iota}=0.34$, and this predictor explains about $34 \%$ of the variance when controlling the other variables.

It should be emphasized that the result of the multiple regression analysis carried out in the group of the pilots independent of the field turned out to be statistically insignificant $\mathrm{F}(5.13)=1.657, \mathrm{p}>0.05\left(\mathrm{r}=0.624, \mathrm{r}_{\iota}=0.389\right.$, corrected $\left.r_{c}=0.154\right)$. Thus, the obtained results confirm the occurrence of individual differences related to the accuracy of maintaining the flight rate under the influence of the sloping cloud tilted $10^{\circ}$ to the right. The results also indicate the occurrence of different cognitive mechanisms affecting the maintenance of the flight rate due to the preferred style.

To verify the hypothesis that during the simulation of visual illusions the pilots that capture the field of view globally (processing information as a whole), compared to the pilots that capture the field locally (fragmentarily), experience a greater spatial disorientation manifested by the change in the flight rate - Student's t-tests for independent samples were used. A positive weak correlation was found between the average rate and the time of task performance in conditions determining the fragmentary style, $r=0.256, p=0.04$, and the global style (in conflict and non-conflict conditions), $r=0.24$, although in this case a weak correlation was obtained at the level of strong tendency, $\mathrm{p}=0.054$. Thus, the pilots with the global style are characterized by a higher value of the flight rate. In the flight rate volatility, a positive weak correlation of the rate value with the time of task performance in the local condition was also obtained ( $\mathrm{r}=0.274, \mathrm{p}=0.027)$.

During the flight phase with the sloping cloud tilted to the left, significant differences in the accuracy of the flight program were discovered between the pilots, $\mathrm{F}(2.62)=3.94$, $\mathrm{p}<0.05$. The pilots with FINT (0.0091) and FD (0.0063) styles differed in aircraft tilting $(\mathrm{p}<0.05)$. Higher roll variation was noted among the pilots with a mixed style. By means of a multivariate regression analysis (performed using an input method), the authors also tried to identify the cognitive predictors of the accuracy of the flight profile performance under the influence of the sloping cloud tilted $10^{\circ}$ to the left. Both variability and asymmetry of the flight performance were analyzed. In the multiple regression model, an important predictor of the accuracy of the flight profile performance was the efficiency of monitoring working memory in the MMATT task $(\beta=0.318$, $\mathrm{p}<0.01$ ), which explains $9.6 \%$ of the variance. The model is significant, $F(3.63)=3.217, p<0.05$. Based on the lower efficiency of the working memory monitoring, it is possible to predict a more left-side asymmetry of heading under the influence of the left-leaning cloud (heading in line with the direction of the cloud's tilt).

In the regression model carried out for the heading fluctuation indicator, the number of false alarm errors in the SWATT task was found to be significant $(\beta=0.453$, $\mathrm{p}<0.001)$. This predictor explains $18.3 \%$ of the variance $(\mathrm{F}(3.61)=5.778, \mathrm{p}<0.01)$.

Based on the efficiency of attention control and working memory, which is manifested by making false alarms while performing 2 tasks at the same time, it is possible to predict greater variability of the flight rate (a less stable flight). The analysis has shown that the lower accuracy of the flight profile, which is manifested by a greater tilting of the aircraft, can be predicted based on the lower efficiency of the search of working memory.

\section{DISCUSSION}

It was revealed that the right sloping cloud (compared to left sloping cloud) had a greater impact on pilots' behavior. It raised more spatial disorientation. Apart from that, not all the cognitive mechanisms that underline spatial disorientation are identical when the orientation of the cloud differs. In earlier publications [21,22], the authors 
presented information about the role of the right sloping cloud which may give a broader look on the subject matter of this paper.

A comparison of the accuracy of the flight profile performance under the influence of the sloping cloud tilted $10^{\circ}$ to the right, and in the control condition, showed that all the pilots changed the flight rate in the direction of the cloud tilting. There was also a higher variability of the flight rate, which is confirmed both in the maximum deviation of the flight rate to the right, compared to the $300^{\circ}$ reference rate (an increase in the value of the rate) and to the left (a decrease in the value of the rate). Thus, the applied experimental manipulation proved to be effective. The pilots succumbed to the illusion of a false horizon. A comparative analysis, including the simulation of false horizon illusion and control condition (without simulation of illusion), and the preferred styles, revealed the following. The sloping cloud tilted $10^{\circ}$ to the right affected the accuracy of the flight profile performance by the pilots dependent on the field to a greater extent than in the independent-style and mixed-style pilots, because in this group the largest right-sided asymmetry of the rate was noted. The field-dependent pilots under the influence of a right tilted cloud, were also characterized by greater variability of the rate. It was confirmed by the indicators of the maximum rate deviation, both to the right and to the left, relative to the benchmark of $300^{\circ}$ (a maximum decrease and increase in the value of the flight rate). The cognitive styles preferred by the pilots result in a varied accuracy of maintaining flight parameters. The most succumbed to the illusion of a false horizon (spatial disorientation) were the pilots depending on the field (based on the rate change). The pilots with mixed styles were characterized with a lower stability of the course. The pilots independent of the field changed the course of the flight to the slightest degree and demonstrated the greatest stability of the flight rate (resistance to spatial disorientation).
The detailed analysis of cognitive determinants of the accuracy of maintaining flight parameters in the condition with the sloping cloud tilted $10^{\circ}$ to the right has shown that the greatest variability of aircraft tilts, under the influence of the sloping cloud in the field of vision, was obtained by the pilots independent of the field and the pilots with a mixed style, while the pilots depending on the field obtained the smallest variation of the aircraft's tilt. It can be concluded that there are differences due to the cognitive style in the method of steering the aircraft. Less smooth control, i.e., a more "reactive style" of the aircraft control, is typical of the pilots with field-independent and mixed styles, compared to a stable way of controlling the plane by the field-dependent pilots (based on the smaller variability of the above mentioned flight parameters). The field-dependent subjects were more deluded by the false horizon than the independent pilots (rate asymmetry), especially when the cloud in the field of view was tilted to the right. There was a change in the flight direction to the right, i.e., in line with the tilting of the cloud in the field of view. There were also differences due to the preferred cognitive styles in maintaining the flight rate (based on variability). A more accurate maintenance of the flight rate was typical of the field-dependent pilots, compared to the pilots with a mixed style. The pilots with dependent and field-independent styles did not differ in terms of the variability of the flight rate, so it can be stated that in terms of maintaining the flight course, both the pilot groups behave similarly. The least stable flight rate was maintained by the pilots with a mixed style (FINT). A mixed cognitive style means less smooth control of the aircraft, which can be described as a "reactive style" of control. The pilots with a mixed style are characterized by high volatility of the rate.

\section{CONCLUSIONS}

This research results show that, in the pilots' recruitment process, it is worth considering the dependence on/the in- 
dependence from the field. Such assessment is, to some extent and in a modified version, currently used in the United States Air Force Aptitude Tests, during recruitment for future military personnel. In future studies, in the context of individual differences, it is also worth taking into account the oculographic measures of flight profile control in the condition of simulated spatial disorientation.

\section{REFERENCES}

1. Previc FH, Ercoline WR. Spatial disorientation in aviation. Reston: American Institute of Aeronautics and Astronautics; 2004.

2. Benson A J. Spatial disorientation - general aspects. In: Ernsting J, Nicholson AN, Rainford DJ, editors. Aviation medicine. Oxford: Butterworth Heinemann; 1999.

3. Witkin HA, Goodenough DR. Cognitive style: essence and origins. Field dependence and field independence. New York: International Universities Press; 1981.

4. Witkin HA, Asch SE. Studies in space orientation: III. Perception of the upright in the absence of a visual field.

J Exp Psychol. 1948;38(5):603-14, https://doi.org/10.1037/ h0055372.

5. Witkin HA, Asch SE. Studies in space orientation: IV. Further experiments on perception of the upright with displaced visual fields. J Exp Psychol. 1948;38(6):762-82, https://doi. org/10.1037/h0053671.

6. Witkin HA, Oltman PK, Raskin E, Karp SA. A manual for the embedded figures tests. Palo Alto: Consulting Psychologist Press; 1971.

7. Bednarek H, Orzechowski J. Cognitive and temperamental predictors of field dependence-independence. Polish Psychol Bull. 2008;39(1):54-65, https://doi.org/10.2478/v10059008-0008-5.

8. Fox E. Interference and negative priming from ignored distractors: The role of selection difficulty. Percept Psychophys. 1994;56(5):565-74, https://doi.org/10.3758/BF03206952.

9. Neill WT, Valdes LA, Terry K. Facilitatory and inhibitory aspects of attention. In: Kramer A, Coles MGH, Logan GD, editors. Converging operations in the study of visual selective attention. Washington D.C.: APA; 1995. p. 209-61.

10. Miyake A, Witzki A, Emerson M. Field dependence-independence from a working memory perspective: A dual-task investigation of the Hidden Figures Test. Memory. 2001;9(4/6): 445-57, https://doi.org/10.1080/09658210143000029.

11. Baddeley AD. Is working memory still working? Am Psychol. 2001;56(11):851-64.

12. Baddeley AD, Della Sala S. Working memory and executive control. In: Roberts AC, Robbins T W, Weisenkrantz L, editors. The prefrontal cortex: Executive and cognitive functions. Oxford-New York: Oxford University Press; 1998. p.9-21.

13. Miyake A, Friedman N, Emerson M, Witzki A, Howerter A, Wager T. The unity and diversity of executive functions and their contribution to complex "frontal lobe" tasks: A latent variable analysis. Cogn Psychol. 2000;41:49-100.

14. Engle RW. What is working memory capacity? In: Roediger HL, Nairne J, Neath I, Surprenant AM, editors. Nature of remembering: Essays in honor of Robert Crowder. Washington, D.C.: APA; 2001. p. 297-314.

15. Baddeley AD, Logie RH. Working memory: The multiplecomponent model. In: Miyake A, Shah P, editors. Models of working memory: Mechanisms of active maintenance and executive control. New York: Cambridge University Press; 1999. p. 28-61.

16. Witkin HA, Oltman PK, Raskin E, Karp SA. A manual for the Embedded Figures Tests. Palo Alto: Consulting Psychologist Press; 1971.

17. Nęcka E. [Inteligencja i procesy poznawcze]. Kraków: Oficyna Wydawnicza „Impuls”; 1994. Polish.

18. Green DM, Swets JA. Signal detection theory and psychophysics. New York: John Wiley and Sons; 1966.

19. Chuderski A, Nęcka E. [Sprawność uwagi a inteligencja: model parametryczny w architekturze poznawczej ACT-R]. Studia Psychol. 2004;42(1):111-24. Polish.

20. McElree B. Working memory and focal attention. J Exp Psychol Learn Mem Cogn. 2001;27(3):817-35, https://doi. org/10.1037/0278-7393.27.3.817. 
21. Bednarek H. [Czy piloci ulegają złudzeniom percepcyjnym? Poznawcze uwarunkowania dezorientacji przestrzennej]. Sopot: Gdańskie Wydawnictwo Psychologiczne; 2011. Polish.
22. Bednarek H, Truszczyński O, Wutke K. Cognitive Determinants of Pilots' Effectiveness Under a False Horizon Illusion. J Aviat Psychol. 2013;23(3):267-87, https://doi.org/10. 1080/10508414.2013.799363.

This work is available in Open Access model and licensed under a Creative Commons Attribution-NonCommercial 3.0 Poland License - http://creativecommons.org/ licenses/by-nc/3.0/pl/deed.en. 